\title{
Capability Evaluation of Ground Support for Emergency Rescue Helicopters
}

\author{
Xiuyan Zhang ${ }^{1,2}$ Ran Liu $^{1}$ Aiwen Yu ${ }^{1}$ \\ ${ }^{1}$ Civil Aviation University of China, Economics and Management College, Tianjin 300300, China \\ ${ }^{2}$ University of Chinese Academy of Sciences, Institutes of Science and Development, Beijing 100190, \\ China
}

Received April 16, 2018

Accepted April 28, 2018

\begin{abstract}
Under the background that the demand for air emergency rescue is increasingly urgent, the ground support for helicopters' taking off and landing safely in disaster area is studied. By defining the connotation and identifying the influencing factors, the evaluation index system is established, including three level indicators. The weights of the indexes are determined by means of questionnaires. The evaluation model is established by using fuzzy comprehensive evaluation method. Finally, the feasibility of the evaluation model is verified taking a helicopter airport in China as an example. The verification results show that the model is beneficial for the government to fully understand the present situation of the ground support for emergency rescue helicopters, and also to provide direction for the related ground support organizations to improve their ground support capability.
\end{abstract}

Keywords: Emergency Rescue; Helicopter; Ground Support; Capability Evaluation

\section{应急救援直升机地面保障能力评价}

\author{
张秀艳 ${ }^{1,2}$ 刘然 $^{1}$ 余爱文 $^{1}$ \\ 1.中国民航大学, 经济与管理学院, 天津 300300, 中国 \\ 2. 中国科学院大学, 科技战略咨询研究院, 北京 100190, 中国
}

摘要: 在航空应急救援需求愈发迫切的时代背景下, 针对直升机在受灾地区安全起降所需的地面 保障工作进行研究。通过内涵界定与影响因素识别, 构建了应急救援直升机地面保障能力评价三 级指标体系, 根据问卷调查结果确定了指标权重, 运用模糊综合评价法建立了应急救援直升机地 面保障能力评价模型。最后, 以国内某直升机机场为例验证了评价模型的可行性, 验证结果表明 该模型既有利于政府部门充分了解我国应急救援直升机地面保障能力的现状, 也可为相关地面保 障单位提高自身地面保障能力提供方向。

关键词：应急救援；直升机；地面保障；能力评价

\footnotetext{
1 作者简介: 张秀艳, 1983.8, 讲师 (博士研究生), 安全管理方向, 天津市东丽区津北公路 2898 号中国民 航大学, 300300, 13802104873, 13802104873@163.com

基金项目号：国家重点研发计划 2016YFC0802601 航空应急救援装备体系和标准体系研究

国家级大学生创新创业训练计划项目 201710059014 航空应急救援单位运行模式构建研究
}

Copyright $(\mathrm{C} 2018$, the Authors. Published by Atlantis Press.

This is an open access article under the CC BY-NC license (http://creativecommons.org/licenses/by-nc/4.0/). 


\section{1 引言}

近年来, 我国公共安全呈现出大灾多发、 多灾并发的态势, 突发事件发生总量大、损失 大、对社会造成的影响越来越引起人们的关 注。航空应急救援作为应急救援中最快速、最 灵活的救援方式, 在各种救援任务中可以发挥 不可替代的作用。而直升机作为航空应急救援 中使用频率最高、参与救援任务种类最多的救 援装备, 却由于起降、天气或油料等保障不力 而无法随叫随到、随救随走。在 2013 年 4 月 发生的雅安地震中, 受灾重灾区适合直升机使 用的起降点较少, 且起降条件较差, 缺少相应 的灯光等助航设施设备, 而直升机很难在能见 度不够的情况下进入灾区展开救援工作, 直升 机顺利运行所需要的油料也得不到保障 ${ }^{[1]}$ 。种 种地面保障条件不到位, 使得直升机不能在第 一时间赶赴灾区, 这极大地浪费了我国的应急 救援资源，也导致灾区人民错过了黄金救援时 间。

直升机地面保障以通航固定起降点地面 保障为主, 以临时铺设起降点为辅。在通航发 展较为成熟的国家中, 通航保障体系中的通航 机场、固定运营基地（Fixed Base Operator, FBO）、飞行服务站 (Flight service station, FSS) 以及维修站（Maintenance Repair\& Operations, $\mathrm{MRO}$ ) 的数量都较多, 且配备了相应的通信、 导航、气象等设施设备, 并安排了专业人士来 进行操作 ${ }^{[2,3]}$ 。我国目前仅有的几家FBO均属于 公务型FBO, 在航空应急救援中能发挥的作用 有限, 而专门为直升机提供维修服务的 MRO 还尚未设立 ${ }^{[4]}$ 。直升机地面保障严重不足所带 来的后果就是直升机在许多地方无处可落, 大 大影响应急救援效率。在这些已有的通航机场 中, 还有许多缺少或者没有及时更新相应的配 备, 如: 导航设施、场道灯光设施, 除雪车、 除冰车等。

而要提高应急救援直升机地面保障水平, 增强航空应急救援能力, 就必须首先掌握和了 解我国当前应急救援直升机地面保障的基本 状况和综合水平。目前, 尚无学者直接针对应 急救援直升机地面保障能力评价问题进行研 究, 但该问题本质上就是能力评价问题。国内 外学者关于能力评价问题的研究主要集中在 应急救援能力、公共服务能力、工作能力和保
障能力评价几个方面。应急救援能力评价主要 关注应急响应处置过程, 通过识别影响因素、 或者进行场景模拟，进而构建评价模型 ${ }^{[5-13]}$; 公共服务能力侧重于从社会一线获取数据, 根 据公共服务类型不同分别构建评价指标体系 ${ }^{[14,15]}$; 工作能力评价集中表现为单个人员工作 能力评价, 如维修人员、医护人员、运动员等, 针对不同的岗位需求分别识别能力影响因素 构建评价模型 ${ }^{[16-21]}$ 。

保障能力评价问题集中体现在对装备设 备、维修、运行、物流、物资相关内容等方面 的保障能力进行评价。如装备设备方面, 张兴 旺等人针对民航空管设备综合保障能力评价 指标的相对性和模糊性, 运用专家函询法和层 次分析法, 分析了影响系统保障能力的关键要 素, 构建了评价指标体系, 运用层次分析法确 定各指标的权重, 运用模糊综合评价法建立了 评估模型 ${ }^{[22]}$; 在维修方面, 林波在系统分析装 备维修保障能力评价理论的基础上, 确定了装 备维修保障能力的评价内容, 建立起具有较强 可操作性的炮兵部队装备维修保障能力评价 指标体系框架 ${ }^{[23]}$; 在运行方面, 江涛分析了机 场运行特征和保障流程, 探讨了机场安全运行 保障能力的内涵和构成要素, 在此基础上提出 了机场安全运行保障能力的评价指标体系和 模型 ${ }^{[24]}$; 在物流方面, 丁鹏玉运用访谈法和文 献统计方法提取应急物流保障能力要素初始 指标, 编制了我国应急物流保障能力评价指标 体系测评量表, 通过对量表调查数据的探索性 因子分析, 构建出我国应急物流保障能力评价 体系 ${ }^{[25]}$; 在物资方面，陈璐在根据不同突发事 件对应急资源的需求差异进行情景设定的基 础上, 构建了基于情景分析的应急资源保障能 力评价指标体系和评价模型, 并用算例验证了 该模型用于评价应急资源保障能力的科学性 和适用性 ${ }^{[26]}$ 。

综上, 根据各种能力评价问题的研究方法 与思路, 得出应急救援直升机地面保障能力评 价问题的解决思路为: 在界定应急救援直升机 地面保障能力内涵的基础上, 识别出应急救援 地面保障能力影响因素, 根据影响因素构建应 急救援直升机地面保障能力评价指标体系, 运 用数学方法构建应急救援直升机地面保障能 力评价模型。 


\section{2 应急救援直升机地面保障能力的内涵及 影响因素}

本文研究的重点为直升机在参与应急救 援过程中安全起降所需的地面保障, 据此给出 应急救援直升机地面保障的定义为: 在灾害事 件发生后, 直升机在受灾地区起飞和降落所需 要的所有地面工作的统称。具体可以分为起降 场地保障、目视助航保障、航空气象保障、通 信导航监视保障与后勤保障。与此相对应, 应 急救援直升机地面保障能力则可以划分为起 降场地保障能力、目视助航保障能力、航空气 象保障能力、通信导航监视保障能力与后勤保 障能力。

\section{1 起降场地保障能力影响因素分析}

起降场地保障是保证直升机顺利起飞降 落的首要条件。直升机起飞区、进近区和离地 区是此类保障的关键因素; 净空条件以及在遇 到不良天气时对于起降场地的保障能力对于 总体起降保障工作有较为重要的影响 ${ }^{[27]}$; 此 外, 保障人员的经验技能和资格管理, 以及起 降场地的维护保养也是影响起降场地保障的 重要因素。

\section{2 目视助航保障能力影响因素分析}

目视助航保障是整个直升机地面保障工 作当中较为重要的一环。目视助航设施设备的 情况是该类保障的关键, 包括指示标、飞行区 地面标志和灯光系统 ${ }^{[28]}$, 其中, 指示标又包括 风向标、着陆方向标等标志, 对于机场地面保 障工作来说指示标的大小、颜色以及形状都代 表了不同的含义, 因此, 机场应保证拥有齐全 的指示标, 且指示标的相关特性符合国家相关 要求。飞行区地面标志的相关要求与指示标的 类似, 主要涉及标志的颜色、大小和形状。灯 光系统用于指示飞行区的边界轮廓、障碍物、 本场标志、风向指示、下滑坡度等, 是航空器 空间或低能见度情况下进行起降的必备系统, 它包括边界灯、障碍灯、风向标志袋、下滑坡 度指示器、标志灯、泛光灯等多种灯具以及控 制器, 对于灯光系统的要求则主要集中在灯具 质量、灯光强度、灯光颜色、灯光发光频率、 灯光的闪光顺序及灯光的摆放位置 ${ }^{[29]}$ 。

\section{3 航空气象保障能力影响因素分析}

灾害发生后出现恶劣气象条件是不可避 免的, 因此航空气象保障在整个地面保障工作 中显得尤为重要。气象人员的数量与专业技能 是影响航空气象保障能力的关键因素 ${ }^{[30]}$ 。航空 气象设备包括常规观测设备 (如电传式风向风 速仪）、图文传真设备、天气雷达、卫星云图 接受处理系统等 ${ }^{[31]}$, 相关要求主要包括在气象 设备的探测范围、分辨率、抗电磁干扰能力、 误码率 (即接收云图的清晰程度) 以及探测所 允许的最大误差 ${ }^{[2]}$ 。

\section{4 通信导航监视保障能力影响因素分析}

通信导航监视保障工作对于直升机的航 行和定位至关重要。通信设备包括高频通信设 备、甚高频通信设备和手持地空对讲机; 导航 设备包括测距仪、全向信标、指点信标等设备; 监视设备则包括一次监视雷达、二次监视雷达 和其他监视设备 ${ }^{[33]}$ 。这些设备需要配套使用, 且需要安装在合理的位置, 其探测范围也是衡 量通信导航监视保障工作的依据。此外电磁环 境与地理环境的良好性也是影响上述设施设 备工作的重要因素 ${ }^{[34]}$ 。

\section{5 后勤保障能力影响因素分析}

后勤保障工作主要包括油料供应保障、供 电保障、特种车辆保障等。由于后勤保障工作 内容较多, 因此保障人员的数量、技术水平和 管理水平均应达到要求。油料保障主要是保证 能够提供充足的质量达标的航油, 拥有足够的 储油设备也是影响油料保障的因素 ${ }^{[35]}$ 。供电保 障则主要是保证供电的稳定性, 防止因为电压 不稳而对相应的航空设施设备造成损坏, 此 外, 备用电源的可靠性对于后勤保障也非常重 要 ${ }^{[36]}$ 。特种车辆保障也是后勤保障的一部分, 主要涉及特种车辆的数量和质量。

\section{3 应急救援直升机地面保障能力评价指标 \\ 体系}

在分析了应急救援直升机地面保障能力 影响因素的基础上，构建应急救援直升机地面 保障能力评价三级指标体系, 一级指标和二级 指标体现应急救援直升机地面保障能力的基 
本构成要素, 方便管理者找到地面保障有缺陷 的方面; 三级指标是衡量应急救援直升机地面 保障能力最有效、最直接的基层元素。不同指 标对于地面保障能力的影响不同, 通过权重大 小来体现。根据指标体系编制影响力度调查问
卷, 通过计算每个选项对应的选择人数占总选 择人数的百分比来确定权重。通过网络向通用 航空工作人员和研究人员发放问卷共计 139 份, 回收 139 份。得到的应急救援直升机地面 保障能力指标体系及权重如表 1 所示:

表 1 应急救援直升机地面保障能力评价指标体系及权重

\begin{tabular}{|c|c|c|}
\hline $\begin{array}{l}\text { 一 级 } \\
\text { 指标 }\end{array}$ & 二级指标 & 三级指标 \\
\hline \multirow{17}{*}{$\begin{array}{l}\text { 起 降 } \\
\text { 场 地 } \\
\text { 保 障 } \\
\text { 能力 } \\
0.328\end{array}$} & \multirow{2}{*}{ 起降保障人员能力 } & 起降场地保障人员数量 0.073 \\
\hline & & 起降场地保障人员专业技能 0.543 \\
\hline & 0.331 & 起降场地保障人员的工作经验 0.384 \\
\hline & \multirow{2}{*}{ 进近起飞和离地区保障能力 } & 区域大小 0.351 \\
\hline & & 区域表面强度 0.441 \\
\hline & 0.298 & 区域坡度 0.208 \\
\hline & \multirow{2}{*}{ 起降场地环境保障能力 0.144} & 起降场地的净空条件 0.573 \\
\hline & & 起降场地应对不良天气的能力 0.427 \\
\hline & 起降管理保障能力 & 起降场地保障人员的培训与考核制度 0.505 \\
\hline & 0.227 & 起降场地的维修保养制度 0.495 \\
\hline & \multirow{2}{*}{ 目视助航保障人员能力 } & 目视助航保障人员的数量 0.082 \\
\hline & & 目视助航保障人员的专业技能 0.553 \\
\hline & \multirow{2}{*}{0.206} & 目视助航保障人员的工作经验 0.365 \\
\hline & & 指示标的齐全性 0.455 \\
\hline & 指示标保障能力 & 指示标的颜色 0.221 \\
\hline & \multirow[t]{2}{*}{0.137} & 指示标的大小 0.267 \\
\hline & & 指示标的形状 0.057 \\
\hline \multirow{5}{*}{$\begin{array}{l}\text { 目 视 } \\
\text { 助 航 } \\
\text { 保 障 } \\
\text { 能力 }\end{array}$} & \multirow{2}{*}{ 飞行区地面标志保障能力 } & 飞行区地面标志的颜色 0.402 \\
\hline & & 飞行区地面标志的形状 0.445 \\
\hline & \multirow{3}{*}{0.217} & 飞行区地面标志的大小 0.153 \\
\hline & & 灯具的质量 0.155 \\
\hline & & 灯光强度 0.262 \\
\hline \multirow{8}{*}{0.132} & 灯光保障能力 & 灯光发光频率 0.188 \\
\hline & \multirow[t]{3}{*}{0.220} & 灯光颜色 0.122 \\
\hline & & 灯光位置 0.203 \\
\hline & & 灯光闪光顺序 0.070 \\
\hline & \multirow{2}{*}{ 目视助航环境保障能力 } & 目视助航设备所在地的地理位置 0.418 \\
\hline & & 目视助航保障工作应对不良天气的能力 0.582 \\
\hline & \multirow{2}{*}{ 目视助航管理保障能力 } & 目视助航设备管理人员培训考核制度 0.427 \\
\hline & & 目视助航设备的维护检查制度 0.573 \\
\hline 航 空 & \multirow{2}{*}{ 气象人员保障能力 } & 气象保障人员的数量 0.054 \\
\hline 气 象 & & 气象保障人员的专业技能 0.561 \\
\hline 保 障 & 0.322 & 气象保障人员的工作经验 0.385 \\
\hline 能力 & 气象设备保障能力 & 气象设备的探测范围 0.205 \\
\hline 0.189 & 0.311 & 气象设备的分辨率 0.194 \\
\hline
\end{tabular}




\begin{tabular}{|c|c|c|}
\hline & & 气象设备的探测允许最大误差 0.224 \\
\hline & & 气象设备的抗电磁干扰能力 0.221 \\
\hline & & 气象设备的误码率 (接收云图清晰程度) 0.156 \\
\hline & 气象环境保障能力 & 气象设备所处地区的电磁环境 0.398 \\
\hline & 0.195 & 航空气象保障工作应对不良天气的能力 0.602 \\
\hline & 气象管理保障能力 & 航空气象人员的培训与考核 0.524 \\
\hline & 0.172 & 航空气象设备的维护制度 0.476 \\
\hline & & 通信导航监视保障人员的数量 0.105 \\
\hline & 通信导航监视人员保障能力 & 通信导航监视保障人员的专业技能 0.562 \\
\hline 通 信 & 0.300 & 通信导航监视保障人员的沟通能力 0.333 \\
\hline 导 航 & 识信已航监视沉各保障能力 & 通信导航监视设备的配套率 0.327 \\
\hline 监 视 & 进信导航监㭠攻备保障能刀 & 通信导航监视设备安装位置合理性 0.530 \\
\hline 保 障 & $0.3 / 2$ & 通信导航监视设备的信号覆盖率 0.143 \\
\hline 能力 & 通信导航监视环境保障能力 & 通信导航监视设备所处的电磁环境 0.602 \\
\hline 0.216 & 0.186 & 通信导航设备所处的地理环境 0.398 \\
\hline & 通信导航监视设备管理能力 & 引导保障人员的培训考核制度 0.476 \\
\hline & 0.142 & 设备维护保养制度 0.524 \\
\hline & 后勒人员保障能力 & 后勤保障人员的数量 0.177 \\
\hline & 吕野人贝保陧能儿 & 后勤保障人员的技术水平 0.464 \\
\hline & 0.268 & 后勤管理人员的管理水平 0.359 \\
\hline & 油料保障能力 & 储油设备的充足性 0.326 \\
\hline 后 勤 & 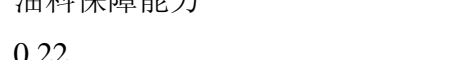 & 油料质量良好性 0.399 \\
\hline 保 障 & & 油料的充足性 0.275 \\
\hline 能力 & 供电保障能力 & 供电的稳定性 0.689 \\
\hline 0.135 & 0.208 & 备用电源的可靠性 0.311 \\
\hline & 特种车辆保障能力 & 特种车辆的数量 0.291 \\
\hline & 0.168 & 特种车辆的质量 0.709 \\
\hline & 后勤管理能力 & 后勤保障人员的培训考核制度 0.524 \\
\hline & 0.136 & 后勤设备等资源的库存补充制度 0.476 \\
\hline
\end{tabular}

建立第二层次因素集: $u_{i}=\left\{u_{i 1}, u_{i 2}, \ldots u_{i n}\right\}$ ，

\section{4 应急救援直升机地面保障能力评价模型}

根据模糊综合评价法构建应急救援直升 机地面保障能力评价模型, 其评价步骤 ${ }^{[37]}$ 如图 1 所示。

\section{1 建立因素集}

评价因素集是指以被评价系统中各个影 响因素为元素所组成的集合, 通常用 $U$ 表示。

建立第一层次因素集: $U=\left\{u_{1}, u_{2}, u_{3}, u_{4}, u_{5}\right\}$, 其中 $u_{1}$ 代表起降场地保障能力, $u_{2}$ 代表目视 助航保障能力, $u_{3}$ 代表航空气象保障能力, $u_{4}$ 代表通信导航监视保障能力, $u_{5}$ 代表后勤保障 能力。
以起降场地保障能力 $u_{1}$ 为例, 即 $u_{1}=$ $\left\{u_{11}, u_{12}, u_{13}, u_{14}\right\}$, 其中 $u_{11}$ 代表起降场地保障 人员能力, $u_{12}$ 代表进近起飞与离地区保障能 力, $u_{13}$ 代表起降场地环境保障能力, $u_{14}$ 代表 起降场地管理能力。

建立第三层次因素集, $u_{i j}=\left\{u_{i j 1}, u_{i j 2}, \ldots u_{i j r}\right\}$, 以起降场地保障人员能力为例, 即 $u_{11}=$ $\left\{u_{111}, u_{112}, u_{113}\right\}$, 其中, $u_{111}$ 代表起降保障人 员数量, $u_{112}$ 代表起降保障人员专业技能, $u_{113}$ 代表起降保障人员工作经验。

\section{2 建立权重集}

根据上节内容建立权重集： $A=$ $\left\{a_{1}, a_{2}, \ldots, a_{m}\right\} ， a_{i}(i=1,2, \ldots ., m)$ 代表相应的因素 


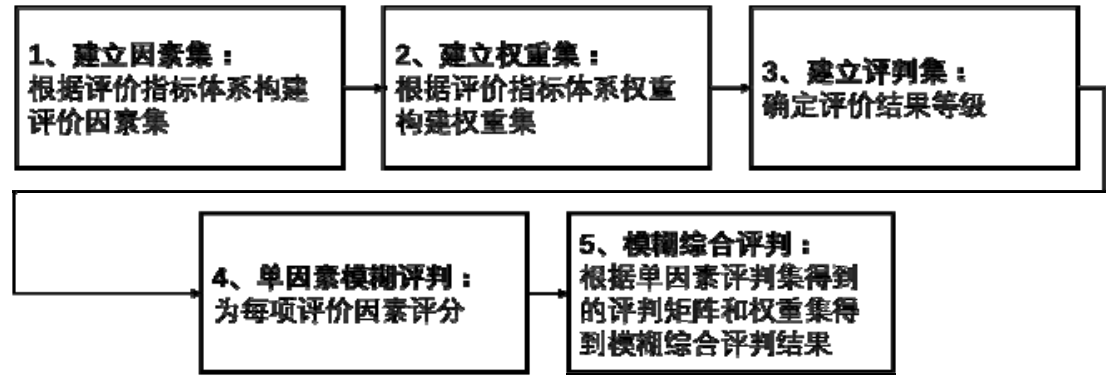

图 1 应急救援直升机地面保障能力评价步骤

对应的权重, 以第一层次为例, $A=\left\{a_{1}, a_{2}, a_{3}, a_{4}\right.$, $\left.a_{5}\right\}$, 其中, $a_{1}=0.328, a_{2}=0.132, a_{3}=0.189$, $a_{4}=0.216, a_{5}=0.135$ 。

\section{3 建立评判集}

评判集是评判者对评判对象可能做出的 各种评判结果所组成的集合, 通常表示为 $V=$ $\left\{v_{1}, v_{2}, \ldots, v_{n}\right\}$ 。将评判结果分为很强、较强、 一般、较弱、很弱五种, 则评判集 $V=\{$ 很强, 较强, 一般, 较弱, 很弱 $\}$ 。

\section{4 单因素模糊评判}

设对因素集 $U$ 中第 $i$ 个元素 $u_{i}$ 进行评判, 对于评判集 $V$ 中第 $j$ 个元素 $v_{j}$ 的隶属度为 $r_{i j}$, 则按照第 $i$ 个元素 $u_{i}$ 的评判结果, 可得出模糊 集合:

$$
R_{i}=\left(r_{i 1}, r_{i 2}, \ldots, r_{i n}\right)
$$

同理, 可得到相应于每个元素的单因素评 判集:

$$
\begin{aligned}
R_{1}= & \left(r_{11}, r_{12}, \ldots, r_{1 n}\right) \\
R_{2}= & \left(r_{21}, r_{22}, \ldots, r_{2 n}\right) \\
& \ldots \ldots \ldots . . . \\
R_{m}= & \left(r_{m 1}, r_{m 2}, \ldots, r_{m n}\right)
\end{aligned}
$$

\section{5 模糊综合评判}

各单因素评判集的隶属度组成矩阵, 又称 为评判矩阵。

$$
R=\left[\begin{array}{ccc}
r_{11} & \ldots & r_{1 n} \\
\ldots & \ldots & \ldots \\
r_{m 1} & \ldots & r_{m n}
\end{array}\right]
$$

根据评判矩阵 $R$ 和权重集 $A$, 则模型综合 决策模型为:

$$
B=A \cdot R
$$

\section{5 实例分析}

以国内某直升机机场为例, 该机场是经军 方批准修建的飞行训练机场。机场包括 1600 米跑道和 $68 \times 800$ 米停机坪，建设 8 个 $35 \times 30$ 米机库和 2200 余平方米的航站航管综合楼, 航行气象、通信导航、供电供油、机务保障、 消防保安等各类设备和车辆一应俱全。能提供 飞行培训、公务飞行、低空旅游、飞行器试航、 应急救援、空中巡查等全面的通航飞行服务, 可满足大多数中小型喷气式公务机的起降。运 用上述评价模型对其应急救援直升机地面保 障能力进行评价, 评价结果如表 2 所示.

根据表 2 最后一行模糊综合评判结果可 以看出，第三项 0.295 明显大于其他四项，而 根据评判集 $V=\{$ 很强, 较强, 一般, 较弱, 很弱 \}，第三项 0.295 对应的是 “一般”，因 此可以说明该直升机机场的航空应急救援地 面保障能力一般。

此外, 还可看出具体某类保障工作的保障 能力, 如起降场地保障能力一般, 其中起降场 地人员保障能力较强, 进近起飞和离地区的保 障能力一般, 起降场地环境保障能力较强, 起 降管理保障能力一般。其他类型保障工作的保 障能力也可同理得出。

\section{6 结语}

本文针对应急救援直升机在受灾地区安 全顺利起降所需的地面保障工作展开研究, 得 出以下结论:

（1）通过对能力评价问题进行研究, 提 炼出了能力评价问题的共性的解决思路, 即; 界定问题内涵、识别问题影响因素、构建评价 指标体系、建立评价模型; 
表 2 某直升机机场地面保障能力评价结果

\begin{tabular}{|c|c|c|c|c|c|c|c|}
\hline 目 & 级 & & & & 平价结果 & & \\
\hline $\begin{array}{l}\text { 标 } \\
\text { 层 }\end{array}$ & 指标 & 二级指标 & 很强 & 较强 & 一般 & 较弱 & 很弱 \\
\hline & 起降 & 起降场地人员保障能力 & 0.1543 & 0.347 & 0.206 & 0.2384 & 0.0543 \\
\hline & 场地 & 进近起飞和离地区保障能力 & 0.2143 & 0.2441 & 0.4208 & 0.1 & 0.0208 \\
\hline & 保障 & 起降场地环境保障能力 & 0.2 & 0.3247 & 0.3 & 0.1 & 0.0573 \\
\hline & 能力 & 起降场地管理保障能力 & 0.1495 & 0.2495 & 0.3 & 0.1505 & 0.1505 \\
\hline & & 起降场地保障能力 & 0.178 & 0.291 & 0.305 & 0.158 & 0.068 \\
\hline & & 目视助航人员保障能力 & 0.1082 & 0.2529 & 0.3928 & 0.1553 & 0.0918 \\
\hline & 目视 & 指示标保障能力 & 0.2057 & 0.3488 & 0.2676 & 0.0512 & 0.0267 \\
\hline & 助航 & 航空地面标志保障能力 & 0.2402 & 0.2359 & 0.3641 & 0.1445 & 0.0153 \\
\hline & 保障 & 灯光保障能力 & 0.2709 & 0.3048 & 0.2553 & 0.1483 & 0.0225 \\
\hline & 能力 & 目视助航环境保障能力 & 0.2164 & 0.2582 & 0.3254 & 0.1 & 0.1 \\
\hline & & 目视助航管理保障能力 & 0.3 & 0.1427 & 0.2427 & 0.1573 & 0.1573 \\
\hline 应 & & 目视助航保障能力 & 0.221 & 0.260 & 0.313 & 0.146 & 0.060 \\
\hline 急 & 航空 & 航空气象人员保障能力 & 0.1615 & 0.3284 & 0.3331 & 0.1385 & 0.0385 \\
\hline 救 & 气象 & 航空气象设备保障能力 & 0.2927 & 0.2639 & 0.3221 & 0.0989 & 0.0224 \\
\hline 援 & 保障 & 航空气象环境保障能力 & 0.3602 & 0.3 & 0.1398 & 0.1602 & 0.0398 \\
\hline 保 & 能力 & 航空气象管理保障能力 & 0.2476 & 0.2 & 0.3524 & 0.1524 & 0.0476 \\
\hline 障 & & 航空气象保障能力 & 0.256 & 0.281 & 0.295 & 0.133 & 0.035 \\
\hline 能 & 通信 & 通信导航监视人员保障能力 & 0.2105 & 0.4229 & 0.2333 & 0.1 & 0.0333 \\
\hline 力 & 导航 & 通信导航监视设备保障能力 & 0.2327 & 0.2143 & 0.3184 & 0.1673 & 0.0673 \\
\hline & 监视 & 通信导航监视环境保障能力 & 0.2602 & 0.3 & 0.2398 & 0.1398 & 0.0602 \\
\hline & 保障 & 通信导航监视管理保障能力 & 0.1476 & 0.2 & 0.4 & 0.2 & 0.0524 \\
\hline & & 通信导航监视保障能力 & 0.219 & 0.291 & 0.290 & 0.147 & 0.053 \\
\hline & & 后勤人员保障能力 & 0.2928 & 0.3105 & 0.2249 & 0.1359 & 0.0359 \\
\hline & 后勤 & 油料保障能力 & 0.2725 & 0.3399 & 0.2 & 0.1275 & 0.0601 \\
\hline & 保障 & 供电保障能力 & 0.2689 & 0.3689 & 0.2689 & 0.0311 & 0.0622 \\
\hline & 能力 & 特种车辆保障能力 & 0.3 & 0.2291 & 0.2709 & 0.1291 & 0.0709 \\
\hline & & 后勤管理能力 & 0.2524 & 0.2 & 0.4 & 0.1 & 0.0476 \\
\hline & & 后勤保障能力 & 0.279 & 0.301 & 0.260 & 0.106 & 0.054 \\
\hline & & 靖救援地面保障能力 & 0.221 & 0.286 & 0.295 & 0.142 & 0.056 \\
\hline
\end{tabular}

(2) 通过对直升机在受灾地区安全起降 所需的地面保障工作进行分析, 得出应急救援 直升机地面保障能力可以分解为起降场地保 障能力、目视助航保障能力、航空气象保障能 力、通信导航监视保障能力和后勤保障能力, 为系统地建立健全直升机地面保障工作提供 切入点;

（3）根据每种类别保障能力影响因素的 识别结果，从人、机、环、管四种系统要素构 成的角度提出了 23 个二级指标和 64 个三级指
标, 为受灾地区直升机地面保障能力改进与提 高工作的具体实施提供指导;

（4）通过实例验证得出，本文构建的应 急救援直升机地面保障能力评价模型能够为 地面保障单位评估自身保障能力和水平提供 有效参考。

基于此, 未来研究工作将围绕以下两方面 展开:

（1）对应急救援直升机地面保障能力评 价指标进行优化, 使其评价结果客观化与定量 
化;

（2）以应急救援直升机地面保障能力评 价工作为基础, 进行应急救援直升机地面装备 配备和人员资质研究及标准研究。

\section{参考文献}

[1] 韩榕,安锦.通航应急救援体系有待建立.中国航 空报,2013,4(2).

[2] National Air Transportation Association. General Aviation in the United States American: NATA, 2009.

[3] Rod Beck A Short of General Aviation FBO's and the Aviation Client [EB/OL]. http://www.getaviation.com/blog/airplanes-business-use-produc tivity/a-short-history-of-general-aviation-fbo\%e2 $\% 80 \% 99$ s-and-the-aviation-client. 2011-10-13.

[4] 于清媛.我国通航运行保障模式发展建议.中国 民用航空,2014,28(3):99-101.

[5] ShaoHua Shang; ChungHwei Su. The Evaluation of Fire Rescue Capability from Post-Earthquake Fires in Taipei, Taiwan.Journal of Earthquake and Tsunami. 2014,8(5):145-147.

[6] 吴新燕.城市灾害救援能力评价指标体系的研 究:(硕士学位论文).河北:河北理工学院,2003.

[7] 迟娜娜.城市灾害应急能力评价指标体系研 究:(硕士学位论文). 北京: 首都经济贸易大 学,2006.

[8] 田依林,杨青.基于 AHP_DELPHI 法的城市灾害 应急能力评价指标体系模型设计.武汉理工大 学学报,2008,32(1):168-171.

[9] 徐吉辉,楚维.基于 AHP_FCE 的航空应急救援能 力评价研究.航空维修与工程,2012,24(3):60-62.

[10] 张丽敏,张琪. 基于 IAHP 法的民用机场应急救 援能力评价. 消防技术与产品信 息,2013,18(12):21-24.

[11] 王晓东, 吴群红. 突发公共卫生事件应急能力评 价指标体系构建研究.中国卫生经济, 2013, 32(6): 47-50.

[12] Olivier SALVI, Samuel DELSINNE, Biogas - A European Perspective on Safety and Regulation, Journal of Risk Analysis and Crisis Response, Vol.1, No. 1 (July, 2011).

[13] Shuzhen Li, Alateng Tuya, Disaster Risk Research Literature on Statistics Analysis in China Journal Net, Journal of Risk Analysis and Crisis Response, Vol. 5, No. 2 (July 2015), 129140.

[14]郡旭. 成都市安全生产公共服务能力评价指标 体系构建研究:(硕士学位论文)成都:电子科技 大学,2015.

[15] 杨丽.贫困地区农村卫生室公共卫生服务能力 评价指标体系初步研究:(硕士学位论文)武汉: 华中科技大学,2014.
[16] Nai Ruo Xing,Xiao Bin Hui. The Post Ability Evaluation of Maintenance Personnel Based on the G1-Topsis Algorithm. Applied Mechanics and Materials,2013,347(12):3051-3055.

[17] 周厚秀.护理本科生临床能力评价指标体系的 研究:(硕士学位论文)重庆:第三军医大学,2006.

[18] 熊否.篮球运动员竞技能力评价指标体系的构 建:(硕士学位论文)武汉:武汉体育大学,2014.

[19] 王彩霞.博士研究生科研能力评价指标体系及 评价方法研究:(博士学位论文)成都:西南交通 大学,2006.

[20]K. Harald Drager, TIEMS DREVS Initiative: Disaster Resilience Establishment for Vulnerable Societies, Journal of Risk Analysis and Crisis Response, Vol. 4, No. 3 (September 2014), 133140.

[21] Tianhan Jiang, Assessment Method of Emergency Preparedness System Vulnerability Based on the Complex Network Theory, Journal of Risk Analysis and Crisis Response, Vol. 2, No. 3 (November 2012), 195-200.

[22] 张兴旺,陶显.基于模糊综合评价的民航空管设 备保障能力评估.价值工程.2012,14(6):25-26

[23] 林波.基于灰色聚类炮兵装备维修保障能力评 价及应用研究:(硕士学位论文)长沙:国防科学 技术大学,2009.

[24] 江涛.机场安全运行保障能力模型研究: 硕士 学位论文)天津:中国民航大学,2014.

[25] 丁鹏玉.我国应急物流保障能力评价指标体系. 物流技术,2015,34(9):140-142.

[26] 陈璐.基于情景分析的应急资源保障能力评价 模式研究:(硕士学位论文)郑州:河南理工大 学, 2014

[27] 刘志浩.机场净空安全保障水平提升方法研 究:(硕士学位论文)天津:中国民航大学,2016

[28] GB/T17836-1999,通用航空机场设备设施.北京: 中国标准出版社,1999.

[29] 徐承东.初探连云港机场灯光保障及战备应急 抢修.江苏航空,1999,28(3):178-179.

[30] Matt Ebbatson, Don Harris. Crosswind Landings in General Aviation: A Modified Method of Reporting Wind Information to the Pilot. The International Journal of Aviation Psychology, 2007, 17(4): 353-370.

[31] MH/T4016.4-2004,民用航空气象第四部分:设 备配备.北京:中国民航出版社,2004.

[32] MH/T4016.5-2004, 民用航空气象第五部分: 设 备技术要求.北京:中国民航出版社,2004.

[33] MH/T5026-2012,通用机场建设规范.北京:中国 民航出版社,2012.

[34] GB6364-86,航空无线电导航台站电磁环境要求. 北京:中国标准出版社,1986.

[35] 张凤.我国通用机场航油保障模式探析.西安航 空学院学报,2016,34(2):9-11.

[36] 王志勇,陈峰.机场供电及助航灯光保障体系设 计与分析.民用航空,2001,24(3):9-10.

[37] 张景林,崔国璋.安全系统工程. 北京:煤炭工业 出版社,2002. 